\section{DISCUSSION}

PV stenosis appears frequently in neonates or infants with congenital heart disease such as total anomalous pulmonary venous connection. PV stenosis can be repaired using several surgical procedures, including a sutureless technique, ${ }^{1,2}$ patchplasty, ${ }^{3}$ excision of the stenosis, ${ }^{3}$ and reimplantation of the PV with direct anastomosis. ${ }^{4}$ The sutureless technique has evolved as a method to treat patients with recurrent PV stenosis developing after repair of total anomalous pulmonary venous connection. This technique requires no direct suturing of the PVs, enabling aggressive resection of the anterior wall of the segmental PV. Thus, the PV confluence can be created as wide as possible, even in complicated cases such as redo procedures. Additionally, oblique incision of the LAAp is key to creating a large atriopericardial anastomosis.

Although various congenital cases have been documented, to the best of our knowledge, only 1 adult case has been previously reported. ${ }^{3}$ In a 43 -year-old man with PV stenosis caused by idiopathic mediastinal fibrosis, pericardial patchplasty was performed for repair. ${ }^{3}$ After that report, we used conventional patchplasty for the first time. Subsequently, the sutureless technique was indicated for recurrent PV stenosis. However, a recent study reported that no significant difference could be found in the primary outcomes between the primary sutureless technique and conventional patchplasty in patients with a total anomalous pulmonary venous connection. ${ }^{1}$ Accordingly, our strategy was considered reasonable and proper for the present patient.

Currently, more than 40,000 cases of catheter ablation are attempted each year in the United States. ${ }^{5}$ PV stenosis induced by ablation occurs in $1 \%$ to $3 \%$ of patients, and most series have not reported the long-term implications or the potential need for surgical intervention. ${ }^{5}$ However, once PV occlusive disease has been established in neonates or infants, no matter how effective, the surgical relief could short term. ${ }^{1}$ These unfortunate patients are plagued by recurrent PV stenosis that eventually translates into mortality. ${ }^{1}$ In adult patients with PV stenosis, balloon angioplasty is recommended as the initial treatment, with stenting as the second choice. Finally, surgical correction would be indicated. Although the sutureless technique was effective in relieving complex forms of PV stenosis as in neonates and infants, it should be cautioned that the sutureless technique also has a known incidence of recurrent PV stenosis. ${ }^{1}$

\section{CONCLUSIONS}

A successful surgical case of recurrent PV stenosis after catheter ablation in an adult is reported. The sutureless technique is effective in preventing reactive hyperplasia of the intima over the connection between the left atrium and the PVs, especially for redo cases after failure of conventional patchplasty.

\section{References}

1. Viola N, Alghamdi AA, Perrin DG, Wilson GJ, Coles JG, Caldarone CA. Primary pulmonary vein stenosis: the impact of sutureless repair on survival. J Thorac Cardiovasc Surg. 2011;142:344-50.

2. Hickey EJ, Caldarone CA. Surgical management of post-repair pulmonary vein stenosis. Semin Thorac Cardiovasc Surg Pediatr Card Surg Annu. 2011;14: 101-8.

3. Van Son JA, Danielson GK, Puga FJ, Edwards WD, Driscoll DJ. Repair of congenital and acquired pulmonary vein stenosis. Ann Thorac Surg. 1995;60:144-50.

4. Pacifico AD, Mandke NV, McGrath LB, Colvin EV, Bini RM, Bargeron LM. Repair of congenital pulmonary venous stenosis with living autologous atrial tissue. J Thorac Cardiovasc Surg. 1985;89:604-9.

5. Holmes DR Jr, Monahan KH, Packer D. Pulmonary vein stenosis complicating ablation for atrial fibrillation. JACC Cardiovasc Interv. 2009;2:267-76.

\title{
Two-stage surgical strategy for aortoesophageal fistula: Emergent thoracic endovascular aortic repair followed by definitive open aortic and esophageal reconstruction
}

\author{
Prashanth Vallabhajosyula, MD, MS, Caroline Komlo, BS, Tyler Wallen, DO, and Wilson Y. Szeto, MD, \\ Philadelphia, $\mathrm{Pa}$
}

\footnotetext{
From the University of Pennsylvania Medical Center, Penn Presbyterian Medical Center, Philadelphia, Pa.

Disclosures: Authors have nothing to disclose with regard to commercial support.

Received for publication Jan 12, 2012; revisions received June 20, 2012; accepted for publication July 30, 2012; available ahead of print Sept 17, 2012.

Address for reprints: Wilson Y. Szeto, MD, University of Pennsylvania Medical Center, Penn Presbyterian Medical Center, 51 N 39th St, PHI Suite 2A, Philadelphia, PA 19104 (E-mail: Wilson.szeto@uphs.upenn.edu).

J Thorac Cardiovasc Surg 2012;144:1266-8

0022-5223/\$36.00

Copyright (C) 2012 by The American Association for Thoracic Surgery

http://dx.doi.org/10.1016/j.jtcvs.2012.07.084
}

Aortoesophageal fistula (AEF) is a rare complication, and is generally fatal without surgical intervention. ${ }^{1}$ Primary causes for AEF formation include foreign body ingestion, ruptured thoracic aortic aneurysms, endograft stenting of the thoracic aorta, advanced esophageal cancer, and surgical procedures involving the esophagus. ${ }^{1}$ Even though there are reports of thoracic endovascular stenting for the treatment of aortoesophageal fistula with early success, ${ }^{1,2}$ late failure and mortality is common. The 

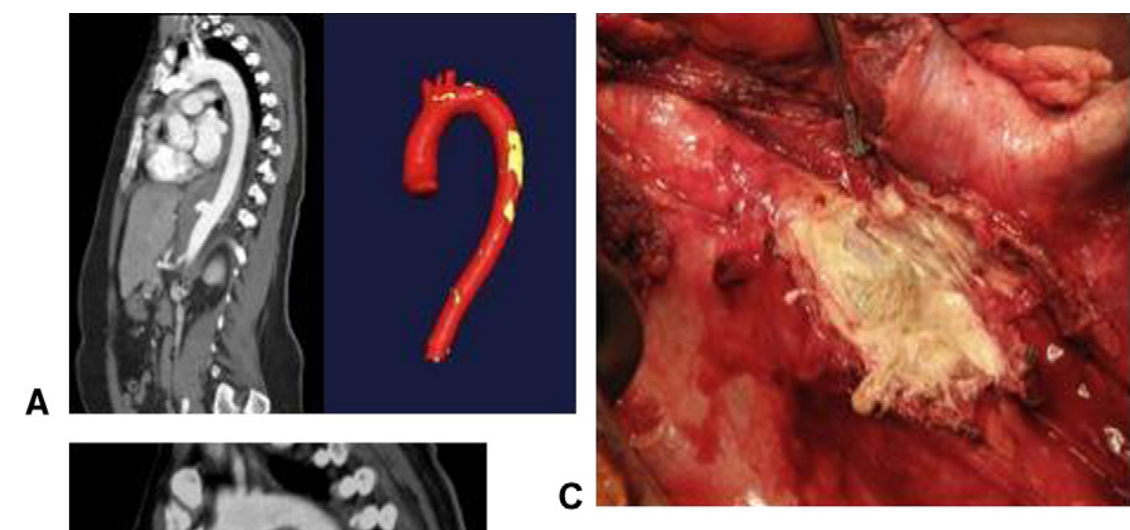

B
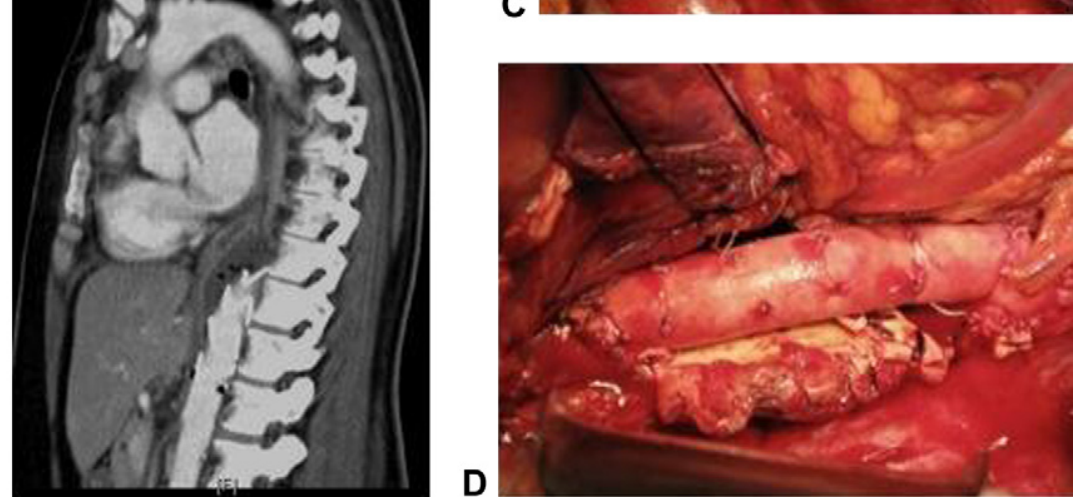

FIGURE 1. Preoperative and post-thoracic endovascular aneurysm repair (TEVAR) imaging, and intraoperative findings. A, Reconstructed image from a contrast computed tomography scan performed at initial presentation shows the thoracic aortic pseudoaneurysm with surrounding phlegmon. B, After emergent TEVAR performed for hemodynamic stabilization, contrast computed tomography scan 10 days later showed the endovascular stent with periaortic air and phlegmon. C, Post-TEVAR, the stabilized patient was taken back to the operating for a definitive repair. Intraoperatively, the endovascular stent was seen immersed in a mediastinal collection of pus. D, The endovascular stent and the involved thoracic aorta were resected, and an interposition homograft was placed.

general consensus challenges the concept of deployment of an endograft prosthesis in the setting of an infected field. We report a case of AEF with gross mediastinal contamination treated in a planned 2-stage approach: initial endovascular stenting of the thoracic aorta as a bridge for patient stabilization, followed by definitive open surgical repair (ie, replacement of the endograft with an aortic homograft, esophageal repair, and wide mediastinal drainage).

\section{CLINICAL SUMMARY}

A 56-year-old woman with a history of achalasia presented to the emergency department in septic shock. She had a week-long history of fever, back pain, and leukocytosis. Two weeks prior, she had undergone upper endoscopy with botulinum injections for achalasia and experienced an episode of hematemesis. In the emergency department, esophagogram failed to show an active AEF, but a computed tomography scan showed a boggy esophagus, mediastinal phlegmon with air, and a leaking thoracic aortic pseudoaneurysm (Figure 1, A). Given her hemodynamic instability and sepsis, the decision was to proceed with a temporizing endovascular procedure, with a subsequent staged definitive open repair. The patient was emergently taken to the operating room for thoracic endovascular aneurysm repair (TEVAR) with a Medtronic Talent (Medtronic Inc, Minneapolis, Minn) proximal main device (Figure 1, $B$ ). Completion angiogram demonstrated no evidence of an endoleak, and no filling of the sacular pseudoaneurysm.

The patient recovered in the intensive care unit during the following week. She was empirically started on broad spectrum antibiotics, including antifungal coverage (eg, vancomycin, cefepime, and fluconazole). Repeat imaging showed a mediastinal abscess with air around the aortic endograft (Figure 1, B). After medical optimization and correction of her septic shock physiology, she was taken back to the operating room for definitive treatment 12 days later. Endoscopy failed to show AEF, although a focal area of inflammation was noted posteriorly. Right video assisted thoracoscopic surgery was performed to widely drain the mediastinum. Next, a left thoracoabdominal incision was made. The mediastinal abscess was identified at the level of the diaphragm and debrided (Figure 1,C). The esophagus was inspected and found to be intact. Her achalasia was definitively addressed with a myotomy + Dor fundoplication 


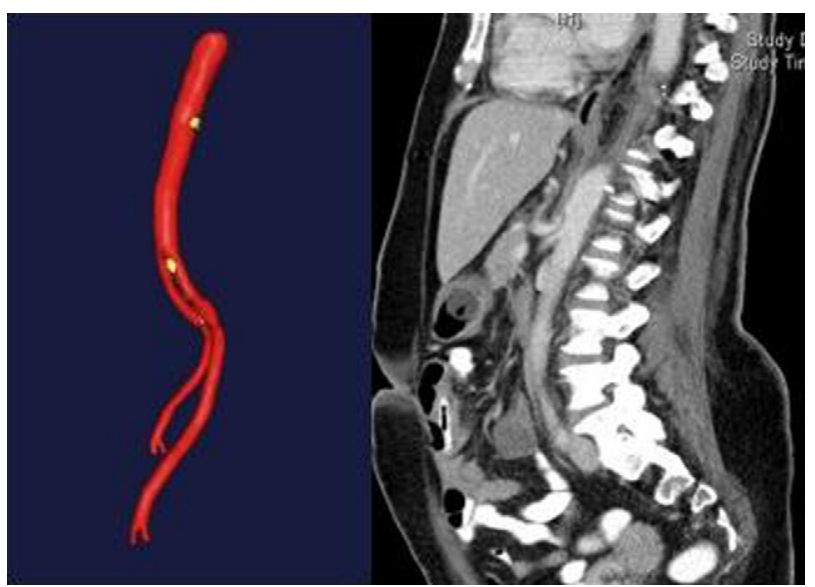

FIGURE 2. Reconstructed computed tomography scan performed at 2-year follow-up showed an intact aortic repair without any pseudoaneurysm formation.

along with jejunostomy tube placement. For the aortic debridement and reconstruction, left atrium-femoral artery bypass was utilized. (Figure 1, D). Aorta and infected endovascular graft were removed, and a cryopreserved homograft was sewn into place in standard fashion (Figure 1, $D)$. Finally, an omental flap was placed.

The patient recovered well from the procedure and was discharged from the hospital. Antibiotics were continued for 10 days postoperatively, and then stopped. At 2-year follow-up, computed tomography scan demonstrated a well-healed posterior mediastinum with an intact aortic repair (Figure 2). Her achalasia symptoms also improved, with significant weight gain and no further dysphagia.

\section{DISCUSSION}

The role of endovascular stent grafting in definitive treatment of AEF remains uncertain. Late infection with rupture and associated mortality rates are high when TEVAR is used as a sole therapeutic strategy. ${ }^{3,4}$ Per 1 retrospective review, ${ }^{3} 4$ of 5 patients treated with TEVAR alone as acute management of AEF died. Of these, 3 patients required additional esophageal surgery later, of which only 1 survived.

In patients with AEF presenting with hematemesis, shock, or sepsis, emergent open surgical repair may also be associated with high mortality. For these patients, we prefer a strategy of a temporizing endovascular procedure to stabilize the patient in extremis, and upon recovery, a definitive open surgical repair at a later time. In a study by Topel et al, ${ }^{5}$ a staged approach to the treatment of AEF was associated with better outcomes than TEVAR alone. In 2 patients presenting with AEF, emergent TEVAR was utilized for patient stabilization, and an open aortic repair with homograft and esophageal repair was performed later. In 2 other patients undergoing TEVAR alone, mortality was $100 \%$. Although those cases represent a very small series, the use of TEVAR as a bridge for later definitive open treatment may be a prudent strategy in the treatment of acute AEF.

The presented case attests to the potential significance of such a staged treatment strategy. Initial TEVAR for patient stabilization in acute AEF would ensure hemodynamic stability and prevent the morbidity and mortality associated with an open repair in such conditions. Clearly, TEVAR does not address the underlying esophageal problem, the fistula, and the associated mediastinal infection. In fact, it introduces prosthetic material into a potentially contaminated field. Therefore, a planned second-stage definitive open operation treating the esophageal condition, replacing the prosthetic endograft with a homograft, along with wide mediastinal drainage, has become our preferred therapeutic strategy for the treatment of patients with AEF. The longevity of the homograft in the descending aortic position is not clear, although we believe it will likely last her lifetime. Literature on aortic homografts typically looked at aortic root replacement. In this situation, homograft failure occured secondary to valve failure. Homograft calcification is a known long-term consequence, but in the descending thoracic aortic position, it would not cause any symptoms.

\section{References}

1. Dossa CD, Pipinos II, Shepard AD, Ernst CB. Primary aortoenteric fistula: part II. Primary aortoesophageal fistula. Ann Vasc Surg. 1999;13:649-52.

2. Burks JA Jr, Faries PL, Gravereaux EC, Hollier LH, Marin ML. Endovascular repair of bleeding aortoenteric fistulas: a 5-year experience. J Vasc Surg. 2001;34: 1055-9.

3. Jonker FH, Heijmen R, Trimarchi S, Verhagen HJ, Moll FL, Muhs BE. Acute management of aortobronchial and aortoesophageal fistulas using thoracic endovascular aortic repair. J Vasc Surg. 2009;50:999-1005.

4. Chiesa R, Melissano G, Marone EM, Kahlberg A, Marrocco-Trischitta MM, Tshomba Y. Endovascular treatment of aortoesophageal and aortobronchial fistulae. J Vasc Surg. 2010;51:1195-202.

5. Topel I, Stehr A, Steinbauer MG, Piso P, Schlitt HJ, Kasprzak PM. Surgical strategy in aortoesophageal fistulae: endovascular stent grafts and in situ repair of the aorta with cryopreserved homografts. Ann Surg. 2007;246:853-9. 